\title{
Optimizing Cathode Materials for Intermediate-Temperature Solid Oxide Fuel Cells (SOFCs): Oxygen Reduction on Nanostructured Lanthanum Nickelate Oxides
}

\author{
Juliana Silva Alves Carneiro ${ }^{a}$, Roger Antunes Brocca ${ }^{a}$, Max Laylson Ribeiro Sampaio Lucena ${ }^{a}$, and Eranda \\ Nikolla $^{\mathrm{a}, *}$ \\ ${ }^{a}$ Department of Chemical Engineering, Wayne State University, Detroit, MI, 48202 USA
}

Corresponding Author:

E-mail: erandan@wayne.edu

Address: 5050 Anthony Wayne Drive

Detroit, MI, 48202

Phone: (313) 577-4159

Fax: (313) 577-3810

(C) 2016. This manuscript version is made available under the Elsevier user license http://www.elsevier.com/open-access/userlicense/1.0/ 


\title{
Optimizing Cathode Materials for Intermediate-Temperature Solid Oxide Fuel Cells (SOFCs): Oxygen Reduction on Nanostructured Lanthanum Nickelate Oxides
}

Juliana Silva Alves Carneiro ${ }^{\mathrm{a}}$, Roger Antunes Brocca ${ }^{\mathrm{a}}$, Max Laylson Ribeiro Sampaio Lucena ${ }^{\mathrm{a}}$, and Eranda Nikolla ${ }^{\mathrm{a}, *}$

${ }^{a}$ Department of Chemical Engineering and Materials Science, Wayne State University, Detroit, Michigan 48202, USA

\begin{abstract}
Kinetics of high temperature oxygen reduction reaction (ORR) on $\mathrm{La}_{2} \mathrm{NiO}_{4+\delta}$ (LNO) nanostructures are investigated by means of electrochemical impedance spectroscopy, with the aim of determining (i) the critical steps that govern ORR in these catalysts, and (ii) ways to lower the overpotential losses associated with these steps. We have identified two main electrochemical processes that govern the polarization resistances during ORR: the electron transfer/oxygen vacancy healing $\left(\boldsymbol{O}_{a d s}+\mathbf{2} \boldsymbol{e}^{-}+\boldsymbol{V}_{\boldsymbol{o}} \Leftrightarrow \boldsymbol{O}_{X}^{\boldsymbol{o}}\right)$, and the oxygen ion transfer through the electrocatalyst/electrolyte interface $\left(\boldsymbol{O}_{L N o}^{2-}+\boldsymbol{V}_{\boldsymbol{o}} \Leftrightarrow \boldsymbol{O}_{X}^{\boldsymbol{o}}\right)$. We find that the nanostructure of LNO significantly effects the activation barriers associated with these processes with nanorodstructured LNO catalyst, highly terminated by [001] surface facets, exhibiting lower barriers compared to traditional, spherical-shaped catalysts. We also show that incorporation of the nanorod-structured LNO as cathode electrocatalysts in SOFCs leads to a significant improvement in the cell performance. These findings provide important insights on the electrochemical steps that govern ORR kinetics on LNO electrocatalyst, and ways to optimize these materials as cathode electrocatalysts for intermediate temperature SOFCs (IT-SOFCs).

\section{Keyword}


Electrocatalysis; Solid oxide fuel cells; Oxygen reduction reaction; Nanostructured nickelate oxides; Impedance spectroscopy.

\section{Introduction}

Oxygen reduction reaction (ORR) plays an important role in many electrochemical energy conversion systems, including solid oxide fuel cells (SOFCs). SOFCs are solid-state electrochemical devices that convert the chemical energy of combustible fuels into electrical energy at elevated temperatures. In these systems, ORR occurs at the cathode and involves the electrochemical reduction of gas phase oxygen to oxygen ions in the presence of electrons $\left(1 / 2 \mathrm{O}_{2}\right.$ $\left.+2 \mathrm{e}^{-}=>\mathrm{O}^{2-}\right)$. This reaction is commonly catalyzed by perovskite-type electrocatalysts that suffer from high overpotential losses, especially when operating under intermediate temperature conditions $\left(500-700{ }^{\circ} \mathrm{C}\right)[1]$. Recent reports have shown that nickelate oxide electrocatalysts with a layered crystal structure exhibit promising activity for ORR, making these systems promising candidates for intermediate-temperature SOFC cathode materials [2-5].

Nickelate oxides are mixed ionic/electronic conducting (MIEC) materials that belong to firstorder Ruddlesden-Popper series, composed of alternating rocksalt and perovskite layers, generally expressed with the formula $\mathrm{A}_{2} \mathrm{MO}_{4+\delta}[6,7]$. They are characterized by the oxygen hyper-stoichiometry in their lattice that is accommodated via the rocksalt-like layers [5, 8]. It has been reported that lanthanum nickelates $\left(\mathrm{La}_{2} \mathrm{NiO}_{4+\delta}, \mathrm{LNO}\right)$ exhibit higher electrochemical ORR activity and improved thermal compatibility with commonly used electrolytes when compared to most traditional perovskite oxides [9]. Furthermore, through a combined theoretical/experimental study, it has been established that the surface structure, controlled by the nanostructure, of lanthanum nickelates plays an important role in their catalytic activity [10, 11]. 
Control over the nanostructure of nickelate oxides can be very challenging when they are incorporated in SOFCs using current state-of-the-art fabrication methods, since these methods involve co-sintering of the electrode electrocatalyst with the electrolyte oxide (i.e., YSZ) at high temperatures (above $1000^{\circ} \mathrm{C}$ ), leading to chemical instability of the electrocatalyst and formation of undesired oxide phases that act as insulators at the electrode/electrolyte interface $[7,19,20]$. This can be circumvented by synthesizing porous scaffolds of ion-conducting oxides, i.e. YSZ, at the electrode that can serve as support for the electrocatalytic particles. Porous oxide scaffold SOFC electrodes have been successfully implemented along with infiltration of metal salts for in-situ synthesis of oxide electrocatalysts [21-23]. The main challenge with co-infiltration of metal salts on porous scaffolds for in-situ synthesis of complex metal oxide electrocatalysts is the limited control over the electrocatalyst nanostructure, and the uniformity in the desired oxide phase within the scaffold matrix. Therefore pre-synthesis of nanostructured oxide electrocatalyst that allows for control over their chemical and geometrical structure is necessary.

In this contribution, we discuss in detail the kinetics of ORR on nanostructured LNO electrocatalyst with the aim of determining (i) the critical steps that govern ORR in these catalysts, and (ii) ways to lower the overpotential losses associated with these steps. Kinetic studies are conducted using symmetric solid oxide electrochemical cells. The LNO nanostructures are synthesized using a reverse microemulsion synthesis method. In order to preserve the nanostructure of the electrocatalyst during the fabrication of the symmetric cells, scaffold-type electrode systems are developed. Our experiments show that the dominant resistances during oxygen reduction on nanostructured LNO electrocatalysts are associated with the vacancy healing/charge transfer step at the electrocatalyst/gas interface and oxygen ion transfer from the electrocatalayst to the electrolyte. We show that the nanostructure of the 
electrocatalytic particles significantly impacts the energetics associated with these steps, with nanorod-shaped lanthanum nickelate exhibiting the lowest barriers as compared to traditional spherical particles. The apparent activation barriers for these processes on nanorod-shaped LNO are $98.43 \pm 0.87 \mathrm{~kJ} / \mathrm{mol}$ and $103.08 \pm 2.78 \mathrm{~kJ} / \mathrm{mol}$, respectively. The overall barrier obtained for ORR on LNO nanorods is $100.91 \pm 1.05 \mathrm{~kJ} / \mathrm{mol}$, which is significantly lower than the ones reported for traditional perovskite-type electrocatalysts [12-14]. In agreement with our kinetic data, SOFCs composed of nanorod-shaped LNO cathode electrocatalyst exhibited improved electrochemical performance (higher power density) when compared to the ones composed of LNO nanospheres. These studies lay the groundwork for tuning the electrocatalytic ORR activity of LNO nanostructures, and open up opportunities for utilizing these materials as cathode electrocatalysts for intermediate temperature SOFCs (IT-SOFCs).

\section{Experimental Methods}

\subsection{Synthesis of $\mathrm{La}_{2} \mathrm{NiO}_{4+\delta}$ Nanostructures}

All chemicals are used as commercially received without further purification. The nanostructured LNO catalyst is prepared using a reverse-microemulsion assisted sol-gel method, as previously reported $[10,11]$. Two systems are separately prepared, each one containing a reverse-microemulsion consisting of cetyltrimethylammonium bromide (CTAB)/water/hexane/nButanol. The first microemulsion is obtained by mixing $\mathrm{La}\left(\mathrm{NO}_{3}\right)_{3} \cdot 6 \mathrm{H}_{2} \mathrm{O}(99.999 \%$, Sigma Aldrich) and $\mathrm{Ni}\left(\mathrm{NO}_{3}\right)_{2} \bullet \mathrm{H}_{2} \mathrm{O}(98 \%$, Alpha Aesar) with deionized water. The second one is obtained by mixing $\mathrm{NaOH}$ (ACS grade, Fisher) and deionized water. After homogeneity is achieved in both systems, the microemulsion containing $\mathrm{NaOH}$ is added to the system containing the metal salts. This final solution is maintained under stirring for 4 hours until a gel suspension 
is obtained. The product is then centrifuged and washed using ethanol and deionized water. This is followed by drying at $80{ }^{\circ} \mathrm{C}$ for 12 hours and calcination at $825^{\circ} \mathrm{C}$ for 2 hours under argon.

\subsection{Synthesis of Electrochemical Cells}

\subsubsection{Symmetric Electrochemical cells}

Two-electrode, symmetric solid oxide electrochemical cells have been widely used to determine the high temperature ORR kinetics on mixed ionic/electronic conducting oxide electrocatalysts $[13,15,24]$. These electrochemical systems are characterized by two identical symmetric electrodes that are separated by an oxygen ion-conducting electrolyte, i.e., YSZ. The YSZ membrane is fabricated by dry-pressing sieved (125 microns) YSZ powder (TZ-8Y, Tosoh) followed by sintering at $1450{ }^{\circ} \mathrm{C}$ for 4 hours in air. Subsequently, a porous YSZ scaffold is synthesized using a ball-milled mixture of YSZ (70 wt\%), graphite (30 wt\%, 99.9995\%, 325 mesh, Alpha Aesar), fish oil (Sigma, from Menhaden), butyl benzyl phthalate (Richard E. Mistler Inc.), polyalkylene glycol (The Dow Chemical Company), and polyvinyl butyral (Richard E. Mistler Inc.), which is sprayed symmetrically on both sides of the sintered YSZ membrane. The assembly is heated to $600{ }^{\circ} \mathrm{C}$ and then sintered at $1450{ }^{\circ} \mathrm{C}$ for 4 hours. The LNO nanorods are dispersed in ethanol by sonication, followed by drop coating $-\sim 1 \mathrm{mg}$ of electrocatalyst - over the YSZ scaffold, and curing at $400{ }^{\circ} \mathrm{C}$ for 3 hours (Fig. 1c).

\subsubsection{Anode-supported SOFCs}

Anode-supported SOFCs are synthesized by initially ball-milling NiO (99\%, Alpha Aesar), YSZ and graphite (1:1:0.6 weight ratio) in ethanol for 48 hours. Subsequently, the slurry is collected, dried, grinded, sieved, and pressed at 3000 psi into pellets (13 $\mathrm{mm}$ diameter). The pellets are sintered at $1100{ }^{\circ} \mathrm{C}$ for 3 hours and the electrolyte solution (YSZ suspended in ethanol) is spin-coated over one side of the porous NiO-YSZ pellet. The anode-electrolyte 
assembly is then sintered at $1450{ }^{\circ} \mathrm{C}$ for 4 hours. The final thickness of the anode and electrolyte layers is $\sim 500 \mu \mathrm{m}$ and $\sim 15 \mu \mathrm{m}$, respectively. A porous YSZ scaffold layer, synthesized as described in Section 2.2.1, is sprayed over the electrolyte side and sintered at $1450{ }^{\circ} \mathrm{C}$. The LNO catalyst is drop coated over the YSZ scaffold, as described in Section 2.2.1, and sintered at 400 ${ }^{\circ} \mathrm{C}$ for 3 hours. The final geometric area of the cathode was $0.1 \mathrm{~cm}^{2}$.

\subsection{Electrochemical Studies}

In all the electrochemical studies, Au mesh (100 LPI, Precision E forming) is used as current collector and Au wires (Alfa Aesar) are used as electrical leads on both electrodes. Au paste (TED Pella) is applied to adhere the electrochemical leads to the electrodes due to its insignificant activity toward oxygen reduction reaction [16]. The cells were attached to the reactor using an $\mathrm{Al}_{2} \mathrm{O}_{3}$-based paste. Electrochemical Impedance spectroscopy (EIS) studies are performed using a Gamry 300 potentiostat (Gamry Inst. Warminster, PA). All polarization resistances are measured under open circuit conditions ( $\mathrm{OCV}$, thermodynamic potential), in a frequency range of $1 \mathrm{MHz}-0.01 \mathrm{~Hz}$, with a $10 \mathrm{mV}$ AC perturbation. The symmetric cells are placed in a single chamber reactor under a controlled $\mathrm{O}_{2} / \mathrm{N}_{2}$ atmosphere (the oxygen partial pressure, $P_{\mathrm{O}_{2}}$, was varied from 0.04 to $1 \mathrm{~atm}$ ). EIS experimental data is fitted using the Gamry EIS300 Electrochemical Impedance Spectroscopy Software.

In the case of the electrochemical studies with SOFCs, the NiO/YSZ anode is reduced overnight at $700{ }^{\circ} \mathrm{C}$ under a flow of $30 \% \mathrm{H}_{2} / \mathrm{N}_{2}\left(20 \mathrm{ml} \mathrm{min}^{-1}\right)$. Linear sweep voltammetry tests are performed with the SOFC cathode exposed to air and the anode exposed to ultra-high purity hydrogen gas $\left(50 \mathrm{ml} \mathrm{min}^{-1}\right)$. The polarization curves (I-V curves) are obtained from OCV to 0.15 $\mathrm{V}$ using a scan rate of $30 \mathrm{mV} / \mathrm{s}$. Electrochemical stability studies are conducted with the SOFC operating in galvanostatic mode at $700{ }^{\circ} \mathrm{C}$ with the current density set at $700 \mathrm{~mA} / \mathrm{cm}^{2}$. In these 
studies the cathode is left open to air, while the anode is exposed to ultra-high purity hydrogen $\operatorname{gas}\left(50 \mathrm{ml} \mathrm{min}^{-1}\right)$.

\subsection{Characterization}

X-ray diffractometer (XRD, D2 Phaser, Bruker) with $\mathrm{Cu} \mathrm{K} \alpha$ radiation $(\lambda=0.15418 \mathrm{~nm})$ is used to characterize the crystal structure of the electrocatalysts before and after the electrochemical studies. The X-ray diffraction patterns are recorded over $2 \theta$ values of $20^{\circ}$ to $80^{\circ}$ with the rate of $0.04 \% \mathrm{~min}$.

The morphology and elemental composition of the electrocatalysts are determined using a field-emission scanning electron microscope (FE-SEM, JSM 7600, JEOL Inc., Japan) equipped with an energy dispersive x-ray spectrometer (EDS). SEM and EDS images were obtaining using an accelerating voltage of $15 \mathrm{kV}$ and working distance of $6 \mathrm{~mm}$. Cross-sectional image of the electrode were obtained by blading the pellet in half through the center region of the electrode.

\subsubsection{Surface Area Measurements}

The two commonly used approaches for defining the electrode active interfacial area in solid oxide electrochemical cells are: (i) using the geometric area of the electrode [17], and (ii) Newman's method [18], which is mainly used to approximate the triple phase boundary region (TPB, the interface between the electrocatalyst, electrolyte and gas-phase). As we discuss in detail below, in mixed ionic/electronic conducting oxides, such as in the case of LNO, the mechanism that governs ORR involves the entire area of the electrocatalyst and the electrocatalyst/electrolyte interface, and it is not limited to the TPB region. As such, the geometric interfacial area of the electrode $(\mathrm{S})$ - interfacial area between the electrolyte disk and the electrode - is used to approximate the active area of the electrode. This method is only applied to the studies in which the nature of the electrocatalyst is not changed. 
In the case when we discuss the effect of the nanostructure of the electrocatalyst (Section 3.4), the cell resistances are normalized by the $\mu$ mols of $\mathrm{O}_{2}$ chemisorbed per physical surface area of the electrocatalyst (LNO). This is obtained by combining $\mathrm{O}_{2}$ chemisorption and $\mathrm{N}_{2}$ physisorption studies using the Micromeritics ASAP 2020 analyzer. The $\mathrm{O}_{2}$ chemisorption studies are used to obtain the $\mu$ mols of $\mathrm{O}_{2}$ chemisorbed per gram of catalyst, while the $\mathrm{N}_{2}$ physisorption is used to determine the physical surface area per gram of catalyst. The procedure for $\mathrm{O}_{2}$ chemisorption studies involves exposing the electrocatalysts to vacuum for 3 hours at $300{ }^{\circ} \mathrm{C}$. This is followed by heating the sample to $500{ }^{\circ} \mathrm{C}$ in inert atmosphere and exposing it to pure $\mathrm{O}_{2}$ in a pressure range from $1-213.55 \mathrm{mmHg}$. The amount of $\mathrm{O}_{2}$ chemisorbed is evaluated by analyzing the plateau region $(20-140 \mathrm{mmHg})$ of the isotherm. In the $\mathrm{N}_{2}$ physisorption studies, the sample is first degassed under vacuum at $350{ }^{\circ} \mathrm{C}$ for 2 hours followed by cooling in liquid nitrogen and performing $\mathrm{N}_{2}$ adsorption - desorption measurements.

All the electrocatalysts are characterized before and after these studies using XRD and SEM to assure that no changes in the structure of the electrocatalysts occurred during these studies.

\section{Results \& Discussion}

\subsection{Synthesis and Characterization of LNO-based Electrodes}

We have used a reverse microemulsion method to pre-synthesize the desired nanostructures of LNO [11], followed by impregnation of these nanostructures on pre-sintered YSZ electrode scaffolds (See Experimental Methods for details). A scanning electron micrograph (SEM) of typical, as-synthesized LNO nanorods is shown in Fig. 1a. 

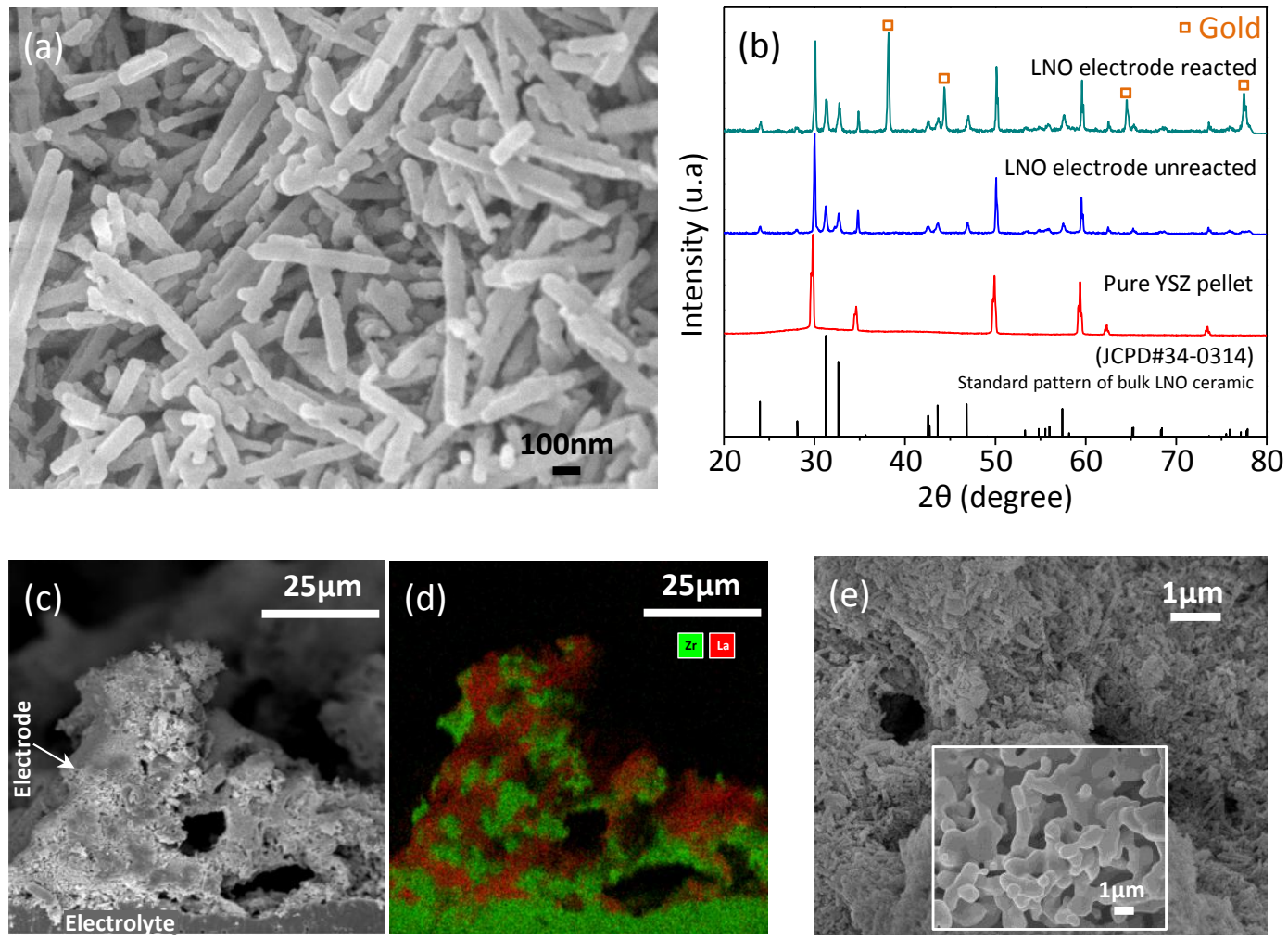

Fig. 1. LNO/YSZ characterization: (a) Scanning electron micrograph (SEM) of LNO nanorods.

(b) Standard pattern for bulk LNO ceramics (black) and XRD spectra of pure YSZ pellet/scaffold (red), LNO nanorods supported on YSZ scaffold (LNO/YSZ electrode) (blue) and LNO/YSZ electrode after electrochemical studies $\left(\mathrm{T}=750-550{ }^{\circ} \mathrm{C}\right)$ (green). (c) SEM of LNO/YSZ scaffold electrode (electrode cross-sectional view). (d) Energy dispersive x-ray spectroscopy (EDS) map of the electrode cross-sectional area shown in (c), where the YSZ scaffold is mapped using zirconia (green) and LNO is mapped using lanthanum (red). (e) SEM image showing top view of LNO nanorods coating and pure scaffold (inset).

Fig. 1b shows the XRD spectra obtained for the synthesized nanostructured LNO/YSZ electrode before and after the electrochemical studies. These XRD spectra are mainly dominated by peaks associated with LNO, YSZ and gold (current collector) as expected, suggesting that no 
detectable secondary crystalline phases were formed between LNO and YSZ during the electrochemical studies, and the crystallite structures of LNO and YSZ were preserved after synthesis and EIS studies. Scanning electron microscopic (SEM) (Figs. 1c and 1e) and energydispersive X-ray spectroscopic (EDS) (Fig. 1d) studies show the microstructure of the LNO/YSZ electrode after synthesis. These images demonstrate the uniformity in the distribution of LNO nanorods over the scaffold surface, as well as the preserved nanostructure of LNO rods after synthesis (Figure 1e). In addition, this approach leads to a fairly large interfacial region between the electrocatalyst and the electrolyte, which should enhance the electrochemical rates.

\subsection{Oxygen Reduction Kinetics using Symmetric Electrochemical Cells}

Typical EIS spectra for a symmetric cell containing YSZ scaffolds at the electrode and LNO nanorods (LNO-nanorods/YSZ|YSZ|LNO-nanorods/YSZ) measured at open circuit voltage $(\mathrm{OCV})$, in an oxygen atmosphere $\left(P_{\mathrm{O}_{2}}=1 \mathrm{~atm}\right)$ and temperatures of 550,650 and $750{ }^{\circ} \mathrm{C}$ are shown in Figs. $2 \mathrm{a}-2 \mathrm{c}$. In these plots $\mathrm{R}_{\text {electrolyte }}$ describes the ohmic resistance induced by the electrolyte, while $\mathrm{Z}_{\text {electrode }}$ describes the electrode polarization resistance obtained from the normalization of the raw complex resistance (excludes ohmic resistance) by the electrode geometric interfacial area $\left(\mathrm{S}=0.1 \mathrm{~cm}^{2}\right)$. Figs. $2 \mathrm{a}-2 \mathrm{c}$ show that $\mathrm{Z}_{\text {electrode }}$ is composed of two main arcs for all temperatures. As the temperature increases, the size of these arcs decreases suggesting that the electrochemical processes that contribute to these resistances are becoming more facile at higher temperatures. 

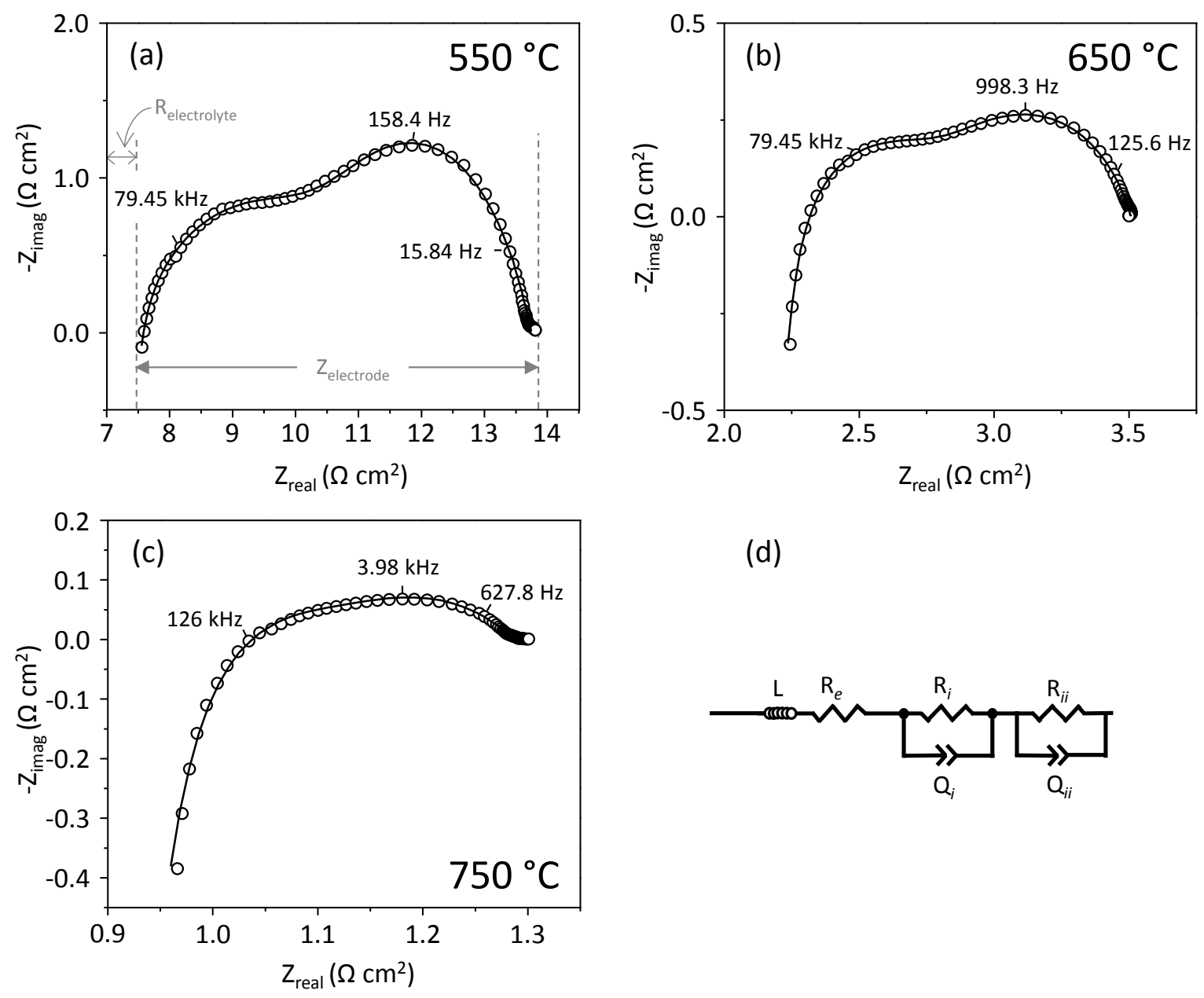

(d)

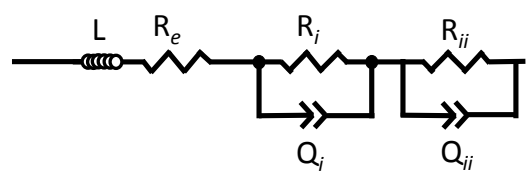

Fig. 2. Electrochemical characterization of symmetric cells: Impedance spectra for LNOnanorods/YSZ|YSZ|LNO-nanorods/YSZ symmetric cells under $P_{O_{2}}=1$ atm at an operating temperature of (a) $550{ }^{\circ} \mathrm{C}$, (b) $650{ }^{\circ} \mathrm{C}$ (c) $750{ }^{\circ} \mathrm{C}$. The polarization resistance of the electrode $\left(\mathrm{Z}_{\text {electrode }}\right)$ is obtained from the normalization of the raw impedance by the electrode area. (d) Equivalent circuit is used to fit of the polarization resistance curves.

It has been shown that ORR can follow distinct pathways in SOFC cathodes based on the properties of the electrocatalyst and the electrocatalyst/electrolyte interface $[25,26]$. The predominant pathway in mixed ionic/electronic conducting oxide electrocatalysts has been shown to involve oxygen adsorption, followed by redox oxygen exchange on the electrocatalyst 
surface $\left(O_{a d s}+2 e^{-}+V_{\ddot{o}} \Leftrightarrow O_{X}^{O}\right)$, and transport of the oxygen ions through the bulk of the mixed ionic/electronic conducting electrocatalysts to the electrocatalyst/electrolyte interface, where the final step occurs involving the oxygen ion transfer at the electrocatalyst/electrolyte interface $\left(O_{\text {electrocatalyst }}^{2-}+V_{\ddot{O}(\text { electrolyte })} \Leftrightarrow O_{X \text { (electrolyte })}^{O}\right)[25,26]$. Since LNO is a mixed ionic-electronic conducting electrocatalyst that exhibits high ion conductivity [8], a similar pathway is assumed to dominate the ORR kinetics on these materials [2].

In order to identify the steps that limit ORR on LNO nanostructures, an analysis of the polarization resistances that arise from the electrochemical steps that govern ORR on LNO, using an equivalent circuit of the type $\mathrm{LR}_{e}\left(\mathrm{R}_{i} \mathrm{Q}_{i}\right)\left(\mathrm{R}_{i i} \mathrm{Q}_{i i}\right)$ (Fig. $\left.2 \mathrm{~d}\right)$ is conducted. This equivalent circuit model is the best fit to the raw EIS data among the models used to describe ORR on mixed ionic-electronic conducting electrocatalysts. In this model, $\mathrm{L}$ accounts for the inductance caused by the electrical connections, $\mathrm{R}_{e}$ represents the ohmic resistance of the YSZ electrolyte, and the circuit elements composed of a resistance in parallel with a constant phase element $\left(\mathrm{R}_{i} \mathrm{Q}_{i}\right.$ and $\mathrm{R}_{i i} \mathrm{Q}_{i i}$ ) represent the two processes that lead to the polarization resistances in the symmetric cells at high frequency $\left(\mathrm{R}_{i} \mathrm{Q}_{i}\right)$ and low frequency $\left(\mathrm{R}_{i i} \mathrm{Q}_{i i}\right)$ ranges.

The activation barriers for the electrochemical processes governing ORR on electrodes containing LNO nanorod electrocatalyst are obtained from the slopes of the plot of the natural $\log$ of the obtained polarization resistances as a function of inverse temperature. This is based on the Arrhenius relationship between the polarization resistance and the activation energy barrier [17]:

$$
R_{a c t}(T)=B \exp \left(\frac{E_{a c t}}{R T}\right)
$$


where $\mathrm{R}_{a c t}$ represents the polarization resistance at a given temperature $(\mathrm{T}), \mathrm{E}_{a c t}$ is the activation barrier for the process exhibiting the polarization resistance, and B represents the pre-exponential factor $\left(\Omega \mathrm{cm}^{2}\right)$ related to the electrode active interfacial area.

Initially, we have determined the activation barriers associated with the polarization resistances described by the two main impedance arcs in Figs. 2a - 2c. Fig. 3a shows the Arrhenius relationships between the polarization resistances $\left(R_{1}\right.$ and $\left.R_{2}\right)$ of the two impedance arcs as a function of inverse temperature. $R_{1}$ and $R_{2}$ are obtained by multiplying the two raw resistances $\left(\mathrm{R}_{i}\right.$ and $\left.\mathrm{R}_{i i}\right)$ of the electrodes by $\mathrm{S} / 2$, in order to normalize by surface area of the electrode (S) and account for the contributions from the two identical electrodes. (See Experimental Methods for details). Based on the slopes of these plots, the activation energies $\left(\mathrm{Ea}_{1}\right.$ and $\left.\mathrm{Ea}_{2}\right)$ associated with the two electrochemical processes described by resistances $\mathrm{R}_{1}$ and $\mathrm{R}_{2}$ are calculated to be $103.08 \pm 2.78 \mathrm{~kJ} / \mathrm{mol}$ and $98.43 \pm 0.87 \mathrm{~kJ} / \mathrm{mol}$, respectively. These activation barriers are very similar in magnitude suggesting that both processes play a significant role in ORR. Fig. 3b shows the overall activation barrier for ORR on LNO nanorods (100.91 \pm $1.05 \mathrm{~kJ} / \mathrm{mol}$ ) based on the area specific resistance (ASR), which is calculated as ASR = $\mathrm{Z}_{\text {electrode }} / 2$. This value is significantly lower than the ones reported for traditional perovskite-type electrocatalysts [12-14], suggesting that these materials are promising electrocatalysts for catalyzing ORR at intermediate temperatures. 

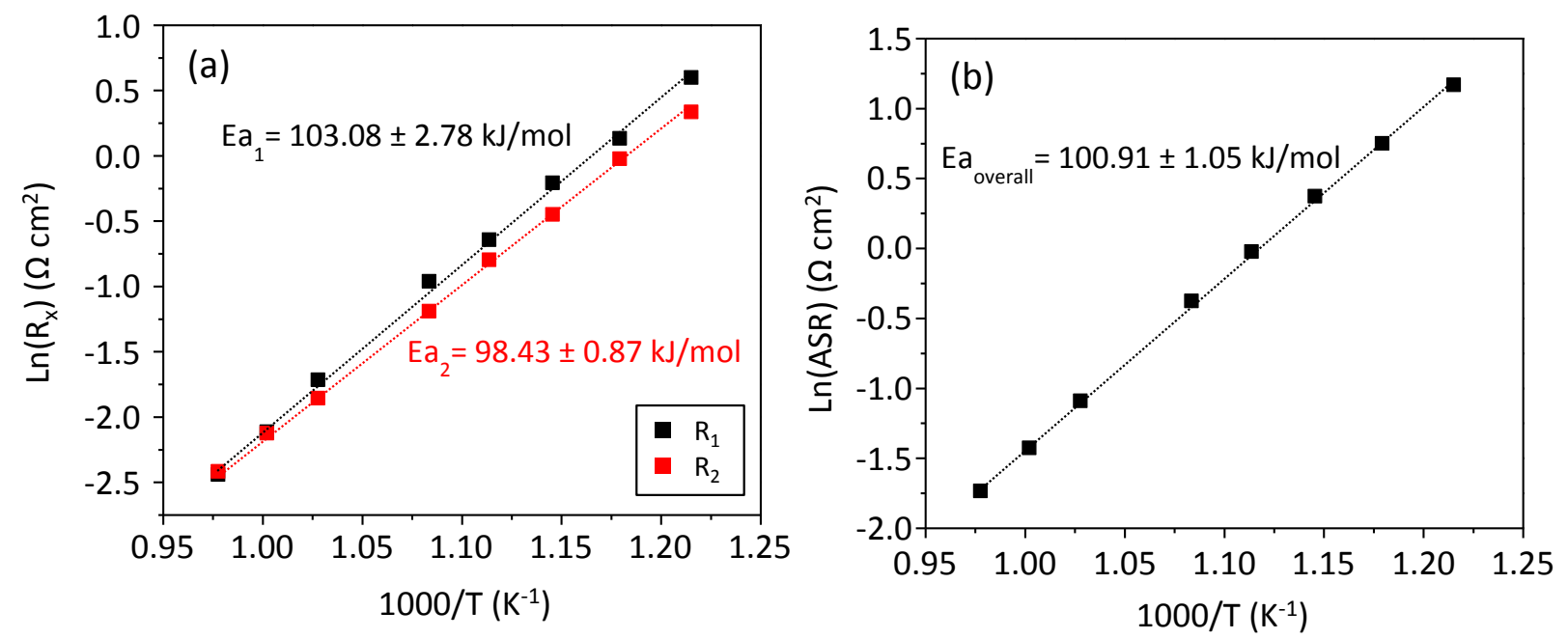

Fig. 3. Kinetics of ORR on symmetric cells containing LNO nanorods: (a) Arrhenius plots of the two main resistances, $\mathrm{R}_{\mathrm{x}}\left(\mathrm{x}=1\left(\boldsymbol{\square}\right.\right.$, black) or $2\left(\boldsymbol{\square}\right.$, red)), during ORR on LNO nanorods at $P_{\mathrm{O}_{2}}$ of $1 \mathrm{~atm}$ and OCV. (b) Arrhenius plot used to determine the overall activation barrier for ORR on LNO nanorod electrocatalysts. The data is obtained using the average of three independent experimental runs for each case.

In order to identify the processes that govern $\mathrm{R}_{1}$ and $\mathrm{R}_{2}$, their dependences on the partial pressure of oxygen, and electrocatalyst nanostructure are investigated.

\subsection{Dependence of the Electrochemical Behavior on Oxygen Partial Pressure}

In the oxygen partial pressure variation studies, we find that the electrode polarization resistance and $P_{\mathrm{O}_{2}}$ are related as $R \sim a\left(P_{\mathrm{O}_{2}}\right)^{-n}$, similar to literature reports $[15,24,27]$. The value of $n$ is experimentally found to characterize the nature of the electrochemical step that occurs at the electrode [18]. The following relationships between $n$ and the electrochemical steps in ORR have been reported [18, 28]:

When $n=1$, the step involves molecular oxygen adsorption: $\boldsymbol{O}_{\mathbf{2}}(g) \Leftrightarrow \boldsymbol{O}_{2, \boldsymbol{a d s}}$

When $n=1 / 2$, the step involves dissociation of gas-phase oxygen to atomic oxygen: $\boldsymbol{O}_{2, \boldsymbol{a d s}} \Leftrightarrow$ $20_{a d s}$ 
When $n=1 / 4$, the step involves charge-transfer/vacancy healing: $\boldsymbol{O}_{\boldsymbol{a d s}}+\mathbf{2} \boldsymbol{e}^{-}+\boldsymbol{V}_{\boldsymbol{o}} \Leftrightarrow \boldsymbol{O}_{X}^{\boldsymbol{O}}$

The correlation between the polarization resistances and $P_{O_{2}}$ are shown in Figs. $4 \mathrm{a}$ and $4 \mathrm{~b}$ in terms of the linear dependence between the $\log$ of the resistances $\left(\mathrm{R}_{1}\right.$ and $\left.\mathrm{R}_{2}\right)$ and the $\log$ of $P_{\mathrm{O}_{2}}$, at high $\left(700{ }^{\circ} \mathrm{C}\right)$ and low $\left(500{ }^{\circ} \mathrm{C}\right)$ temperatures. The plots show that the polarization resistances decrease as the partial pressure of oxygen increases. From the slopes of the plots in Fig. 4a, $n$ values of 0.08 and 0.125 are obtained. These $n$ values are lower than any of the cases discussed above, making it difficult to relate this resistance to any of the ORR steps mentioned above. On the other hand, the dependence of $\mathrm{R}_{2}$ on $P_{\mathrm{O}_{2}}$ is higher, with a slope of approximately 0.2 for both temperatures, suggesting that $\mathrm{R}_{2}$ describes the polarization resistance of a chargetransfer/vacancy healing step $\left(\boldsymbol{O}_{\boldsymbol{a d s}}+\mathbf{2} \boldsymbol{e}^{-}+\boldsymbol{V}_{\ddot{\boldsymbol{O}}} \Leftrightarrow \boldsymbol{O}_{\boldsymbol{X}}^{\boldsymbol{O}}\right)$.

In order to identify the electrochemical step associated with $\mathrm{R}_{1}$, the dependence of the capacitance on the partial pressure of $\mathrm{O}_{2}$ is analyzed. Capacitance values are indicative of the electrode region involved in a particular electrochemical process (i.e., electrocatalyst surface, electrocatalyst bulk, electrocatalyst/electrolyte interface) $[15,24,25,29,30]$. Capacitance is related to the polarization resistance as: $C_{x}=\frac{\left(R_{x} Q_{x}\right)^{\frac{1}{k_{x}}}}{R_{x}}$ (Eqn 2), where $k$ is a parameter that indicates the similarity of $\mathrm{Q}$ (the non-ideal capacitor) to a true capacitor $(\mathrm{C})$, obtained from model fitting. We have calculated the capacitance values associated with both $R_{1}$ and $R_{2}$ at different oxygen partial pressures and temperatures. We find that the values of $\mathrm{C}_{1}$ (capacitance associated with $\mathrm{R}_{1}$ ) are approximately $10^{-7}$ to $10^{-6} \mathrm{~F}$ (Fig. $4 \mathrm{c}$ ), or $10^{-6}$ to $10^{-5} \mathrm{~F} / \mathrm{cm}^{2}$. These capacitance values fall within the range of the double-layer capacitances [29], and are similar to the interfacial polarization capacitances reported for a Pt/YSZ interface $\left(10^{-6}\right.$ to $\left.10^{-5} \mathrm{~F} / \mathrm{cm}^{2}\right)$ [25]. As such, our results suggest that $\mathrm{R}_{1}$ is associated with a process at the electrocatalyst/electrolyte 
interface, such as the oxygen ion transport through this interface, $\left(\boldsymbol{O}_{\boldsymbol{L} \boldsymbol{N} \boldsymbol{O}}^{2-}+\boldsymbol{V}_{\boldsymbol{O}} \Leftrightarrow \boldsymbol{O}_{X}^{\boldsymbol{O}}\right)$. This is consistent with literature reports that show that processes with weak oxygen partial pressure dependence and capacitances around $10^{-6} \mathrm{~F}$, are associated with the oxygen ion transport from the electrocatalyst to the electrolyte $[15,31]$. In the case of $R_{2}$, the capacitance values $\left(\sim 10^{-4}\right.$ to $10^{-3} \mathrm{~F}$, or $10^{-3}$ to $10^{-2} \mathrm{~F} / \mathrm{cm}^{2}$ ) are found to be similar to the ones associated with processes involving the adsorption and exchange of oxygen on a Pt electrode $\left(\sim 10^{-3} \mathrm{~F} / \mathrm{cm}^{2}\right)$ [25]. This is consistent with assigning $\mathrm{R}_{2}$ to overpotential losses associated with the charge-transfer/surface vacancy healing reaction step $\left(O_{a d s}+2 e^{-}+V_{\ddot{O}} \Leftrightarrow O_{X}^{O}\right)[15,24,30,31]$.
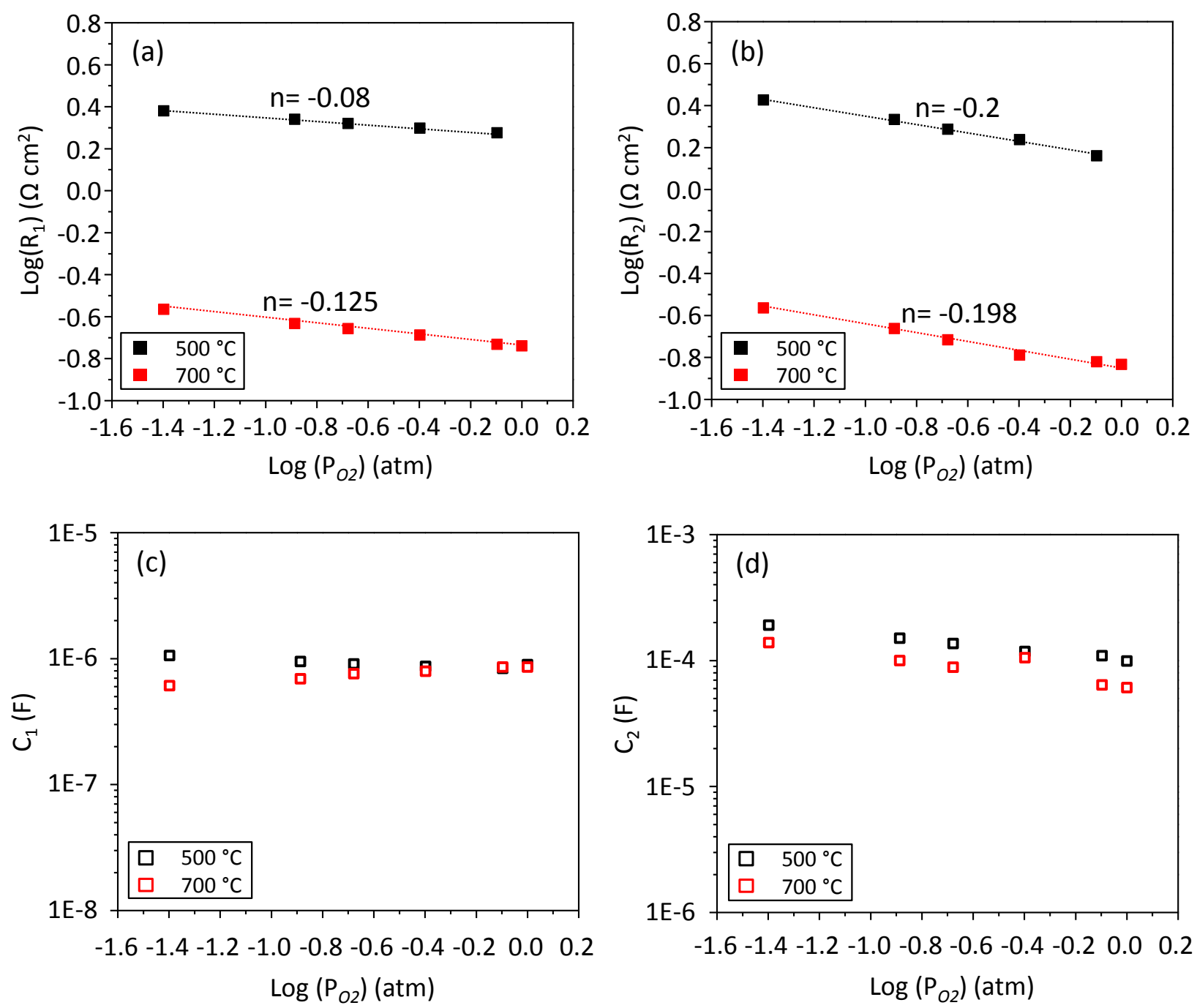

Fig. 4. Dependence of the polarization resistances and capacitances on the oxygen partial 
pressure: (a) $\mathrm{R}_{1}$ and (b) $\mathrm{R}_{2}$ on the oxygen partial pressure at $700{ }^{\circ} \mathrm{C}\left(\boldsymbol{}\right.$, red) and $500{ }^{\circ} \mathrm{C}$ black). (c) Dependence of capacitance, $\mathrm{C}_{1}$, on the oxygen partial pressure at $500{ }^{\circ} \mathrm{C}(\square$, black) and $700{ }^{\circ} \mathrm{C}\left(\square\right.$, red), and (d) Dependence of $\mathrm{C}_{2}$ on the oxygen partial pressure at $500{ }^{\circ} \mathrm{C}$ and 700 ${ }^{\circ} \mathrm{C}$.

\subsection{Dependence of the Electrochemical Behavior on the Electrocatalyst Nanostructure}

The effect of electrocatalyst nanostructure (well-structured nanorods $v s$. traditionally used spheres (truncated polyhedrons)) on the electrochemical kinetics associated with ORR on LNO/YSZ electrodes is also investigated. In these studies, symmetric cells with porous scaffold electrodes are employed. Figs. 5a and 5b show scanning electron micrographs of the scaffoldtype electrodes impregnated with LNO nanorods and nanospheres, respectively.
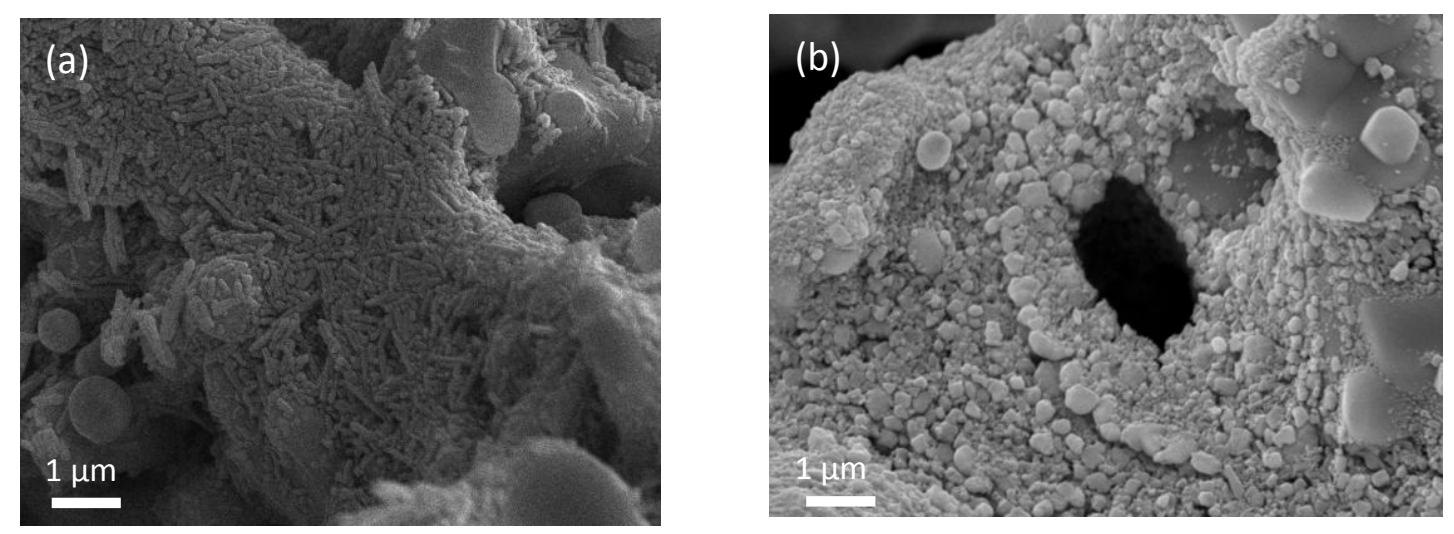

Fig. 5. Scanning electron microscopy of electrodes containing: (a) LNO nanorods and (b) LNO nanospheres.

Figs. $6 \mathrm{a}$ and $6 \mathrm{~b}$ show the Arrhenius plots (measured from 550 to $700{ }^{\circ} \mathrm{C}$ ) and the energy barriers associated with the charge transfer/vacancy healing and oxygen ion transport through the electrocatalyst/electrolyte interface steps on porous electrodes containing LNO nanorods and LNO nanospheres. In these plots, the polarization resistances are normalized per $\mu$ mol of $\mathrm{O}_{2}$ chemisorbed per surface area of the electrocatalyst (Details are found in the Experimental 
Section). It is clear from these results that the electrodes containing LNO nanospheres exhibit higher activation barriers for both steps $\left(\mathrm{Ea}_{1 \text {, nanospheres }}=116.1 .087 \pm 1.087 \mathrm{~kJ} / \mathrm{mol}\right.$ and $\mathrm{Ea}_{2}$, nanospheres $=125.84 \pm 6.87 \mathrm{~kJ} / \mathrm{mol})$ than the ones containing $\mathrm{LNO}$ nanorods $\left(\mathrm{Ea}_{1, \mathrm{rods}}=103.2 .78 \pm\right.$ $2.78 \mathrm{~kJ} / \mathrm{mol}$ and $\mathrm{Ea}_{2, \text { rods }}=98.43 \pm 0.87 \mathrm{~kJ} / \mathrm{mol}$ ). This consistent with our reported density functional theory calculations [11], which showed that (001) NiO terminated surface facets of LNO (that mainly dominate the surface of LNO nanorods) exhibited the highest rates for oxygen exchange as compared to [111], [100] and [001] LaO terminated LNO surfaces. Our calculations suggested that this was due to the fact that the (001) $\mathrm{NiO}$ terminated LNO surface provides the best compromise between the energy associated with surface oxygen vacancy formation and the energy required for dissociative adsorption of oxygen. This is supported by the results obtained here, which show that the symmetric cells containing LNO nanorods exhibit a much lower activation barrier $\left(\mathrm{Ea}_{2, \text { rods }}=98.43 \pm 0.87 \mathrm{~kJ} / \mathrm{mol}\right)$ for the charge transfer/vacancy healing step than symmetric cells containing $\mathrm{LNO}$ spheres $\left(\mathrm{Ea}_{2}\right.$, nanospheres $\left.=125.84 \pm 6.87 \mathrm{~kJ} / \mathrm{mol}\right)$. We find that the overall ORR activation barrier is lower for cell containing LNO nanorods as compared to the ones with LNO nanospheres. This reinforces the fact that the surface structure of LNO plays a key role in the chemistry-associated with ORR. These findings also demonstrate that the charge transfer/vacancy healing and oxygen ion transport through the electrocatalyst/electrolyte interface steps are key steps at controlling ORR kinetics on nickelate oxides. 

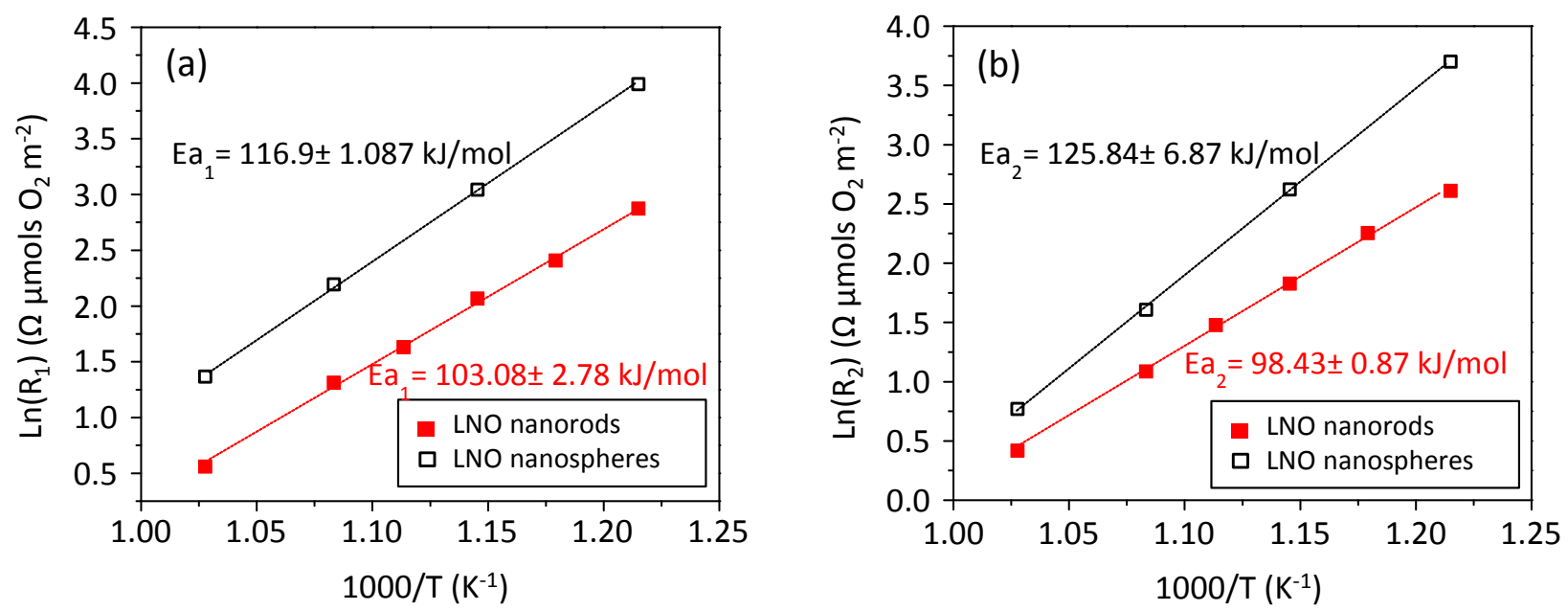

Fig. 6. Kinetics of ORR on LNO electrocatalyst with different nanostructures: Arrhenius plots of (a) $\mathrm{R}_{1}$ and (b) $\mathrm{R}_{2}$ for symmetric cells containing LNO nanorods ( $\mathbf{\square}$, red) vs. the ones containing LNO nanospheres ( $\square$, black). The data is obtained using the average of three independent experimental runs per each case.

\subsection{Electrochemical Performance of LNO Nanostructures in SOFCS}

LNO nanostructures are incorporated as cathode electrocatalysts in anode-supported SOFCs. All cells contained identical anodes composed of Ni/YSZ, and thin YSZ electrolytes. The details are found in the Experimental Section. The cells were tested at different temperatures with the cathode exposed to air, while the anode was exposed to $\mathrm{H}_{2}$ at a total flow rate of $50 \mathrm{ml}$ $\min ^{-1}$. Fig. 7 shows the I-V and power density curves for the SOFCs containing LNO nanospheres (Fig. 7a) and LNO nanorods (Fig. 7b) at the cathode at 600 and $700{ }^{\circ} \mathrm{C}$. Figure 7 shows that the cells containing LNO nanospheres led to maximum power densities of $\sim 121$ and $321 \mathrm{~mW} \mathrm{~cm}^{-2}$ at 600 and $700{ }^{\circ} \mathrm{C}$, respectively, and current densities of $\sim 0.41$ and $1 \mathrm{~A} \mathrm{~cm}^{-2}$ at 600 ${ }^{\circ} \mathrm{C}$ and $700{ }^{\circ} \mathrm{C}$, respectively. The cells containing LNO nanorods achieved much higher power densities of $\sim 176$ and $575 \mathrm{~mW} \mathrm{~cm}{ }^{-2}$ at $600{ }^{\circ} \mathrm{C}$ and $700{ }^{\circ} \mathrm{C}$, respectively, and current densities of 
$\sim 0.57$ and $1.62 \mathrm{~A} \mathrm{~cm}^{-2}$ at $600{ }^{\circ} \mathrm{C}$ and $700{ }^{\circ} \mathrm{C}$, respectively. Significant improvement in the performance of the SOFCs containing LNO nanorods is observed, especially at $700^{\circ} \mathrm{C}$. At lower temperature (i.e. $600{ }^{\circ} \mathrm{C}$ ) the performance differences between cells containing LNO rods and spheres is not as significant. This is due to the fact that at temperatures below $700{ }^{\circ} \mathrm{C}$, the oxygen conductivity through the YSZ electrolyte starts becoming a challenge [32], and suppresses the impact of the cathode electrocatalyst on the overall performance of the cell. Therefore, the incorporation of the LNO nanorod electrocatalysts in SOFC systems containing high oxygen conducting electrolyte membranes (i.e., cerium-based oxide conductors [33]) should improve the performance of these cells even further at intermediate temperatures [13], [12].

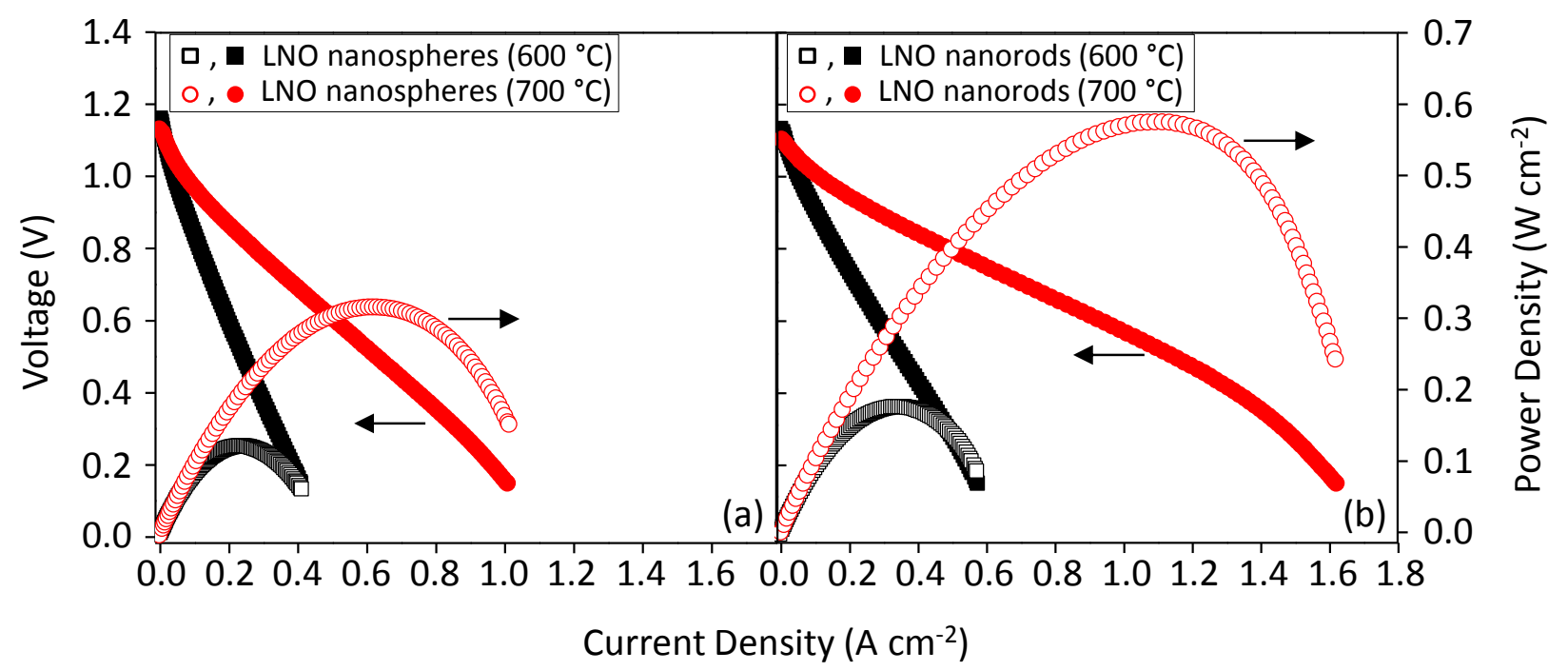

Fig. 7. Electrochemical performance of SOFCs containing LNO electrocatalyst with different nanostructures: (a) LNO nanospheres, and (b) LNO nanorods. Current density (solid markers) and power density (open markers) curves for cells operated at $600^{\circ} \mathrm{C}$ (black square) and $700^{\circ} \mathrm{C}$ (red circle).

Stability of the nanostructure of LNO has also been tested under SOFC operating conditions. Fig. 8a shows the results of the stability test for an anode-supported SOFC with the 
cathode containing LNO nanorods operated at $700{ }^{\circ} \mathrm{C}$ under constant current of $700 \mathrm{~mA} / \mathrm{cm}^{2}$. The cell voltage was monitored over 130 hours under these conditions. In this study, the anode was exposed to $50 \mathrm{ml} \mathrm{min} \mathrm{m}^{-1} \mathrm{H}_{2}$ and the cathode was left open to air. A stable performance was maintained for over 130 hours of operation. Figs. 8b and 8c show scanning electron micrograph and XRD spectra of the reacted SOFC cathodes containing LNO nanorods, respectively. Figs. 8b and 8c show that no changes in the crystal structure (as corroborated by XRD, Fig. 8b) or nanostructure of the catalysts occurred under reaction conditions. These studies suggest that the LNO nanorods, in addition to exhibiting superior performance to LNO spheres, are also very stable under reaction conditions.
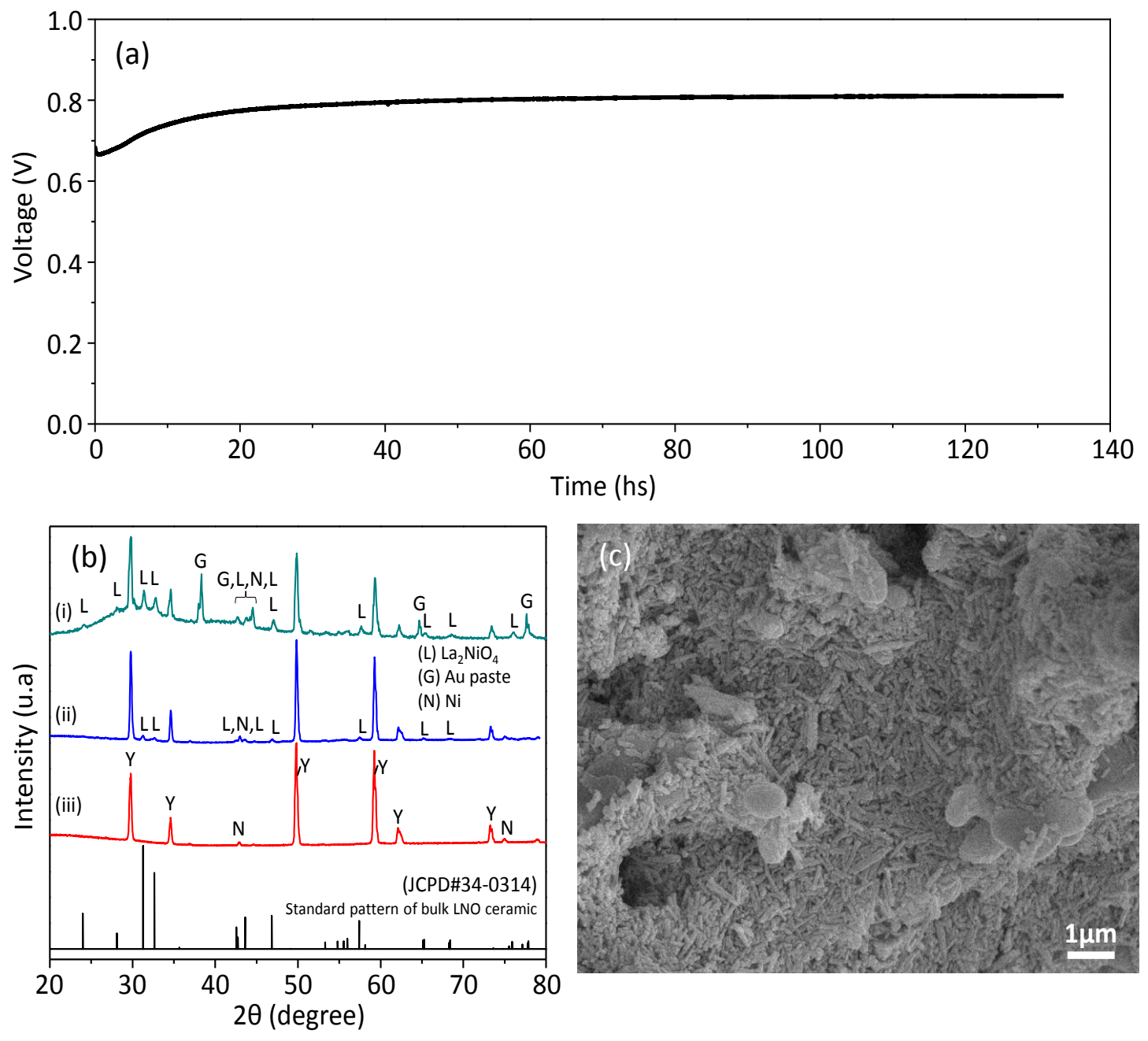
Fig. 8. Stability test of anode-supported SOFC with the cathode containing LNO nanorods: (a) Galvanostatic test (at $700 \mathrm{~mA} / \mathrm{cm}^{2}$ ) measured over 130 hours of SOFC operating at $700{ }^{\circ} \mathrm{C}$ with cathode open to air and anode expose to $50 \mathrm{ml} \mathrm{min}^{-1} \mathrm{H}_{2}$. (b) XRD spectra of post-reacted cell: (i) SOFC after electrochemical studies, (ii) SOFC before reaction, and (iii) baseline - cell containing $\mathrm{NiO} / \mathrm{YSZ}$ anode, YSZ electrolyte and cathode YSZ scaffold. Note that gold paste was used for the cell assembly and peaks related to this element can be detected in the post-reacted pellets. (c) Scanning electron micrograph of SOFC cathodes containing LNO nanorods after 130 hours of operation.

\section{Conclusions}

We have established that there are two main processes that govern ORR on LNO electrocatalysts: charge transfer/surface oxygen vacancy healing at the electrocatalyst/gas interface and oxygen ion transport through the electrocatalyst/electrolyte interface. We find that varying the nanostructure of the LNO (from nanorods to nanospheres (truncated polyhedrons)) significantly affects the activation barriers associated with ORR, with LNO nanorods exhibiting lower overall ORR activation barrier $(100.91 \pm 1.05 \mathrm{~kJ} / \mathrm{mol})$ as compared LNO spheres (120.56 $\pm 1.76 \mathrm{~kJ} / \mathrm{mol}$ ). We also report that incorporating the LNO nanorods in SOFC cathodes significantly improves the electrochemical cell performance. These findings suggest that (i) enhancing the ORR activity of LNO for operation at intermediate temperatures will require finding ways to lower the activation barriers associated with the charge transfer/surface oxygen vacancy healing and oxygen ion transport through the electrocatalyst/electrolyte interface steps, and (ii) the nanostructure of LNO plays a role in catalyzing these processes and can be used as a tool to improve their activity at intermediate temperatures. 


\section{Acknowledgements}

We gratefully acknowledge the support of the National Science Foundation (CBETCAREER 1350623) and Wayne State University. We also acknowledge the help from Dr. Xianfeng Ma with synthesizing and characterizing LNO nanostructures.

\section{References}

[1] C. Xia, W. Rauch, F. Chen, M. Liu, Solid State Ionics. 149 (2002) 11-19.

[2] R. Sayers, M. Rieu, P. Lenormand, F. Ansart, J.A. Kilner, S.J. Skinner, Solid State Ionics. $192(2011) 531-534$.

[3] F. Chauveau, J. Mougin, F. Mauvy, J.M. Bassat, J.C. Grenier, Int J Hydrogen Energ. 36 (2011) 7785-7790.

[4] K.N. Jung, J.H. Jung, W.B. Im, S. Yoon, K.H. Shin, J.W. Lee, Acs Appl Mater Inter. 5 (2013) 9902-9907.

[5] M.S.D. Read, M.S. Islam, F. King, F.E. Hancock, J Phys Chem B. 103 (1999) 1558-1562.

[6] J.C. Grenier, F. Mauvy, C. Lalanne, J.-M. Bassat, F. Chauveau, J. Mougin, J. Dailly, M. Marrony, ECS Transactions. 25 (2009) 2537-2546.

[7] H. Zhao, F. Mauvy, C. Lalanne, J.-M. Bassat, S. Fourcade, J.-C. Grenier, Solid State Ionics. 179 (2008) 2000-2005.

[8] J.M. Bassat, P. Odier, A. Villesuzanne, C. Marin, M. Pouchard, Solid State Ionics. 167 (2004) 341-347.

[9] S.J. Skinner, J.A. Kilner, Ionics, 5 (1999) 171-174.

[10] X.F. Ma, J.S.A. Carneiro, X.K. Gu, H. Qin, H.L. Xin, K. Sun, E. Nikolla, Acs Catal. 5 (2015) 4013-4019. 
[11] X. Ma, B. Wang, E. Xhafa, K. Sun, E. Nikolla, Chem Commun. 51 (2015) 137-140.

[12] J.G. Lee, J.H. Park, Y.G. Shul, Nature communications. 5 (2014).

[13] Z. Shao, S.M. Haile, Nature. 431 (2004) 170-173.

[14] E.P. Murray, T. Tsai, S.A. Barnett, Solid State Ionics. 110 (1998) 235-243.

[15] F. Mauvy, C. Lalanne, J.M. Bassat, J.C. Grenier, H. Zhao, L.H. Huo, P. Stevens, J

Electrochem Soc. 153 (2006) A1547-A1553.

[16] M. Mamak, G.S. Métraux, S. Petrov, N. Coombs, G.A. Ozin, M. Green, J Am Chem Soc. 125 (2003) 5161-5175.

[17] A. Leonide, Y. Apel, E. Ivers-Tiffee, ECS Transactions. 19 (2009) 81-109.

[18] E. Siebert, A. Hammouche, M. Kleitz, Electrochim Acta. 40 (1995) 1741-1753.

[19] A.M. Hernández, L. Mogni, A. Caneiro, Int J Hydrogen Energ. 35 (2010) 6031-6036.

[20] F. Figueiredo, J. Labrincha, J. Frade, F. Marques, Solid State Ionics. 101 (1997) 343-349.

[21] S. Choi, S. Yoo, J.-Y. Shin, G. Kim, J Electrochem Soc. 158 (2011) B995-B999.

[22] G. Yang, C. Su, R. Ran, M.O. Tade, Z. Shao, Energ Fuel. 28 (2013) 356-362.

[23] X. Zhang, H. Zhang, X. Liu, J Power Sources. 269 (2014) 412-417.

[24] M.J. Escudero, A. Aguadero, J.A. Alonso, L. Daza, J Electroanal Chem. 611 (2007) 107116.

[25] S.B. Adler, Chem Rev. 104 (2004) 4791-4844.

[26] A.K. Opitz, M. Kubicek, S. Huber, T. Huber, G. Holzlechner, H. Hutter, J. Fleig, J Mater Res. 28 (2013) 2085-2105.

[27] F. Mauvy, J.-M. Bassat, E. Boehm, J.-P. Manaud, P. Dordor, J.-C. Grenier, Solid State Ionics. 158 (2003) 17-28. 
[28] Y. Takeda, R. Kanno, M. Noda, Y. Tomida, O. Yamamoto, J Electrochem Soc. 134 (1987) 2656-2661.

[29] X. Ge, C. Fu, S.H. Chan, Phys Chem Chem Phys. 13 (2011) 15134-15142.

[30] A.P. Khandale, S.S. Bhoga, J Power Sources. 268 (2014) 794-803.

[31] A. Montenegro-Hernandez, L. Mogni, A. Caneiro, Int J Hydrogen Energ. 37 (2012) 1829018301.

[32] B.C. Steele, A. Heinzel, Nature. 414 (2001) 345-352.

[33] E. Ivers-Tiffee, A. Weber, D. Herbstritt, J Eur Ceram Soc. 21 (2001) 1805-1811. 

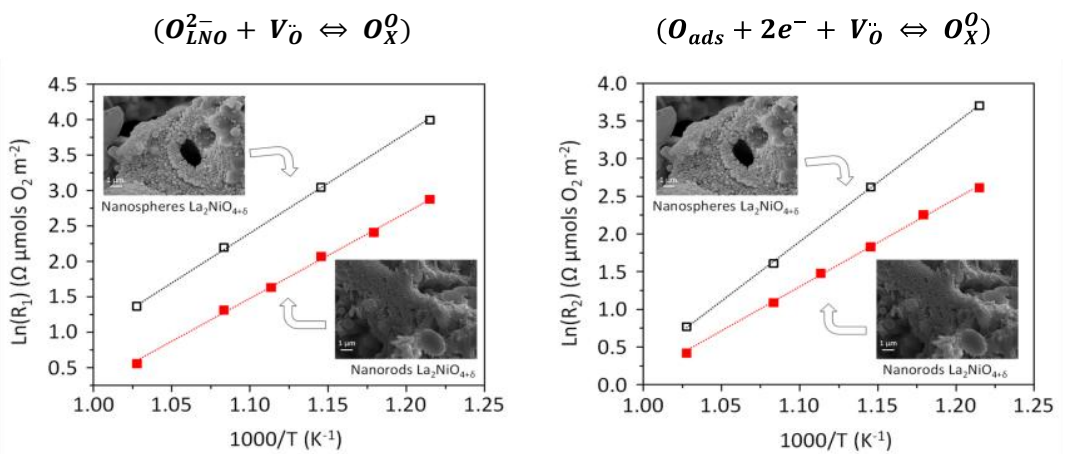

Graphical Abstract 